\title{
PEMBERDAYAAN KADER KESEHATAN MELALUI PENYULUHAN DAN PELATIHAN "GOLDEN AGE PERIOD FOR GOLDEN GENERATION SEBAGAI UPAYA PENINGKATAN KUALITAS BANGSA" PADA KADER KESEHATAN DI WILAYAH PUSKESMAS PANGKALAN LADA PANGKALAN BUN
}

\author{
${ }^{1}$ Angela Ditauli Lubis \\ ${ }^{1}$ STIKes Borneo Cendekia Medika Pangkalan Bun \\ ${ }^{1}$ Email : angela.lubis03@gmail.com
}

\begin{abstract}
ABSTRAK
Kemajuan sebuah bangsa sangat ditentukan oleh individu-individu yang berada di dalamnya. Indonesia merupakan negara berkembang yang masih sangat memerlukan tunastunas bangsa yang dapat membawa kemajuan untuk negara Indonesia ini. Tunas-tunas bangsa yang cerdas berwawasan luas serta mempunyai moral yang baik menjadi harapan bangsa. Hal ini sejalan juga dengan program pemerintah dalam peningkatan kualitas SDM. Untuk mencapai tujuan program ini perlu diupayakan agar segenap anak Indonesia dapat tumbuh dan berkembang secara optimal baik fisik maupun psikis. Namun, semakin berkembangnya waktu harapan belum sesuai dengan kenyataan. Golden age period adalah masa-masa dimana otak anak berkembang sangat pesat dan paling cepat dalam menyerap informasi. Periode emas merupakan suatu periode yang sangat vital atau sesuatu yang sangat penting dalam suatu siklus. Periode emas pada anak yaitu masa-masa penting dimana otak atau kecerdasan anak sangat berkembang pesat. Periode emas berada pada batas umur anak 0-3 tahun. Program pengabdian masyarakat ini dilaksanakan pada hari Kamis, 8 Februari 2018 di wilayah Puskesmas Pangkalan Lada. Metode dalam pelaksanaan pengabdian masyarakat ini menggunakan metode ceramah dalam penyampaian materi kepada peserta dan diskusi. Perlu diadakannya penyuluhan kesehatan dengan topik yang berbeda untuk meningkatkan pengetahuan kader, ibu bayi/balita dan keluarga
\end{abstract}

Kata kunci : Kader, Periode Emas, Orang Tua

\author{
EMPOWERMENT OF HEALTH CARE THROUGH TRAINING AND TRAINING \\ "GOLDEN AGE PERIOD FOR GOLDEN GENERATION AS AN EFFORT TO \\ IMPROVE THE QUALITY OF THE NATION "IN HEALTH CAREER REGENCY IN \\ PANGKALAN PUBLIC HEALTH AREAS PANGKALAN BUN
}

\begin{abstract}
The progress of a nation is very much determined by individuals on board .Indonesia is developing countries that are still very need not davidic people who can bring progress to state indonesia. Of the people who would have a broad outlook not davidic smart moral and hers is better to be the hope of the nation. This is in accordance also with government programs to improve the quality of human resources. To accomplish a purpose these programs need to be indonesia efforts should be made so that all you can grow and optimized both physically and psychologically. But, hope the progress of time have not been in accordance by the fact.The golden age period is times of where a child brain develops very rapidly and most quickly in absorb information. A period of gold is a period of a very vital or something that is abnormally important in some cycle.A period of gold on child that is times of important where the brain or artifice kids are really developed rapidly. A period of gold was on the boundary o my son 3-0 defeat years .The program devotion the community was
\end{abstract}


carried out on thursday, february 82018 in the region of puskesmas pepper base.A method of in the implementation of the devotion talk in this population uses the method for the delivery of material to the members and discussion. Need to bourse health counseling with a different topic to increase knowledge cadres, the child mother and under-fives and family

\section{Keyword: caders, a period of gold, parents}

\section{Pendahuluan}

Kemajuan sebuah bangsa sangat ditentukan oleh individu-individu yang berada di dalamnya. Indonesia merupakan negara berkembang yang masih sangat memerlukan tunas-tunas bangsa yang dapat membawa kemajuan untuk negara Indonesia ini. Tunas-tunas bangsa yang cerdas berwawasan luas serta mempunyai moral yang baik menjadi harapan bangsa. Hal ini sejalan juga dengan program pemerintah dalam peningkatan kualitas SDM. Untuk mencapai tujuan program ini perlu diupayakan agar segenap anak Indonesia dapat tumbuh dan berkembang secara optimal baik fisik maupun psikis. Namun, semakin berkembangnya waktu harapan belum sesuai dengan kenyataan.

Golden age period adalah masamasa dimana otak anak berkembang sangat pesat dan paling cepat dalam menyerap informasi. Periode emas merupakan suatu periode yang sangat vital atau sesuatu yang sangat penting dalam suatu siklus. Periode emas pada anak yaitu masa-masa penting dimana otak atau kecerdasan anak sangat berkembang pesat. Periode emas berada pada batas umur anak 0-3 tahun.

Perkembangan otak adalah perkembangan yang tidak kasat mata seperti perkembangan fisik anak, oleh karena itu perkembangan otak anak sering sekali diabaikan oleh orang tua. Dalam perkembangan otak anak pada periode emas ini sangat diperlukan peran serta orang tua dalam mendukung perkembangan anak agar perkembangan otaknya menjadi optimal.

Penting untuk diketahui setiap orangtua, bahwa proses perkembangan dan pertumbuhan otak anak dimulai sejak ia masih dalam kandungan, hingga anak berusia 3 tahun. Pada masa-masa inilah sel-sel saraf otak berkembang sangat pesat. Otak janin mengalami periode pertumbuhan cepat (brain growth spurt) pertama kali pada saat kehamilan trimester ketiga. Pada trimester ketiga ini, sel neuron (sel-sel otak) pada otak besar membelah dan membagi dengan cepat. Masa pertumbuhan emas otak (brain growth spurt) tahapan kedua terjadi saat bayi baru lahir sampai usia 3 tahun. Usia bayi 0-6 bulan sangat disarankan untuk diberikan ASI eksklusif. ASI mengandung nutrisi yang cukup hingga bayi berusia 6 bulan. Menginjak usia 6 bulan sampai 3 tahun bayi mulai diberi makanan sesuai kebutuhan tubuhnya. Asupan zat gizi adalah faktor utama yang berperan meningkatkan kecerdasan otak secara optimal. Jika pada masa ini bayi tidak mendapatkan kebutuhan gizinya, kekurangannya tak akan bisa dipenuhi lagi di kemudian hari. Karena itu, penting untuk bisa memenuhi kebutuhan nutrisi seimbang di usia ini.

Stimulasi adalah rangsangan yang datang dari lingkungan luar anak. Stimulasi merupakan hal yang sangat penting dalam tumbuh kembang anak. Anak yang mendapat stimulasi yang tearah akan lebih cepat berkembang dibandingkan dengan anak yang kurang atau bahkan tidak mendapat stimulasi. Setiap bayi yang lahir memiliki 100 milyar sel otak. Namun meski setiap bayi memiliki jumlah sel otak yang sama, optimalisasi penggunaan otak belum tentu sama pada setiap anak. Pasalnya belum semua sel-sel otak bayi saling terhubung dengan sempurna. Padahal semakin kuat hubungan antar sel, semakin kuat pula daya tangkap dan 
memori anak. Jumlah hubungan antar sel saraf tersebut menjadi dasar untuk memori pada manusia.

Periode emas merupakan pertumbuhan dan perkembangan anak yang sangat pesat. Di masa-masa inilah, peran orang tua dituntut untuk bisa mendidik dan mengoptimalkan kecerdasan anak baik secara intelektual, emosional dan spriritual. Cara dalam memberikan stimulasi/rangsangan anak pada masa golden age guna mengoptimalkan kecerdasan mereka.

Dari uraian di atas dapat disimpulkan bahwa peran orang tua sangat penting pada masa periode emas anak. Jika orang tua mengetahui betapa pentingnya periode emas tersebut untuk perkembangan otak anak secara optimal maka orang tua pasti ingin memberikan yang terbaik untuk anak-anaknya, karena mempunyai anak yang cerdas adalah dambaan setiap orang tua apalagi anak yang berguna bagi nusa dan bangsa.

\section{Metode}

Program pengabdian masyarakat ini dilaksanakan pada hari Kamis, 8 Februari 2018 di wilayah Puskesmas Pangkalan Lada. Metode dalam pelaksanaan pengabdian masyarakat ini menggunakan metode ceramah dalam penyampaian materi kepada peserta dan diskusi.

\section{Hasil dan Pembahasan}

Peserta penyuluhan sangat antusias dengan materi yang diberikan, adanya buku panduan dan leaflet sangat membantu untuk dapat dibaca kembali di rumah. Kegiatan dapat berjalan dengan baik dan mendapat dukungan dari berbagai pihak, dilakukan demonstrasi selama pelatihan dapat meningkatkan pemahaman peserta, buku modul dapat menjadi sumber belajar yang lebih selain yang disampaikan oleh pembicara dan dapat dibaca kembali di rumah.

\section{Kesimpulan dan Saran Kesimpulan}

Pengabdian masyarakat ini banyak memberikan manfaat bagi kader kesehatan, ibu bayi/balita dan keluarga (ayah, nenek, kakek), bentuk nyatanya adalah adanya peningkatan pengetahuan. Setelah terjadi peningkatan pengetahuan diharapkan tumbuhnya sikap kesadaran akan pentingnya Golden Age Period atau masa emas pertumbuhan, dan untuk kader kesehatan diharapkan dapat mengaplikasikan ilmu yang diterima dalam training (pelatihan) dalam kehidupan sehari-hari dan diharapkan dapat terjadi transfer knowledge (transfer ilmu pengetahuan) dari kader kesehatan terhadap masyarakat sekitar.

\section{Saran}

1. Diadakan penyuluhan kesehatan dengan topik yang berbeda untuk meningkatkan pengetahuan kader, ibu bayi/balita dan keluarga

2. Diadakan pelatihan kesehatan dengan topik yang berbeda untuk meiningkatkan pengetahuan dan ketrampilan kader kesehatan.

\section{Daftar Pustaka}

Moersintowati, Sularyo TS, Soetjiningsih, dkk. 2002. Buku Ajar tumbuh Kembang Anak Edisi ke-1. IDAI.

Soetjiningsih. 1995. Tumbuh Kembang Anak. EGC: Jakarta.

Soetjiningsih. 1997.ASI: Petunjuk Untuk Tenaga Kesehatan. EGC: Jakarta.

Roesli, Utami. 2000. Mengenal Asi Ekslusif. Niaga Swadaya.

Pedoman Kader Seri Kesehatan Anak. Kementerian Kesehatan RI. 2010

Modul PelatihanMakanan Pendamping Air Susu Ibu (MP-ASI). Perinasia.2014. 